


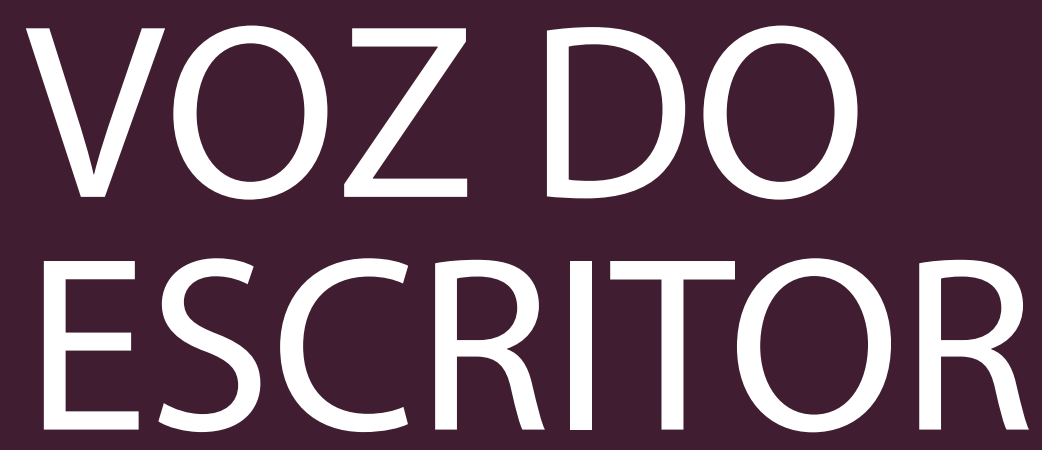




\title{
O QUE EU QUERIA FALAR SOBRE MARÍLIA GARCIA
}

\author{
- JULIA PASINATO IZUMINO
}

$\mathrm{M}$ arília Garcia é tradutora, editora e cofundadora da Luna Parque, editora independente de livros de poesia. Foi cocriadora e curadora da

Revista Modo de Usar e Co., ao lado de Angélica Freitas e Ricardo Domeneck, revista on-line que colecionou uma enorme variedade de poetas do mundo todo. Escreve colunas para jornais e revistas, aparece em festivais e eventos sobre literatura e, claro, é poeta. Até agora publicou seis livros, sendo o primeiro, 20 poemas para o seu walkman, de 2007.

Se eu escolhi começar a minha fala apresentando as credenciais de Marília não é por acaso; é porque, me parece, todas essas atividades que realiza com, sobre, a partir da poesia evidenciam uma relação polivalente com o texto poético, como se conhecesse a poesia por suas diversas facetas e, o que nos importa aqui, incorporasse todos esses modos na sua própria produção - nos seus procedimentos, nos seus temas, nas suas formas.

Por isso me parece acertado falar na prática artística de Marília Garcia, considerando uma espécie de atitude que faz o esforço para incorporar ao texto lírico esse universo de referências que atravessam o seu campo de atuação, tendo a investigação da forma poética e a experimentação com o texto, o discurso e, cada vez mais, a imagem como os seus princípios norteadores.

Existem três pontos principais dessa prática artística sobre os quais eu gostaria de falar com vocês.

O primeiro diz respeito ao que se escreve. Arrisco dizer que todos os poemas de Marília Garcia são, a seu modo, narrativos. Em 20 poemas para o seu walkman - que, apesar do título, tem poemas muito marcadamente visuais -, os textos comparativamente curtos nos trazem micronarrativas, mas como se despidas de tudo o que não é absolutamente necessário. O que sobra são as ações, em um estado quase bruto, que passam a definir os sujeitos. Os personagens, raramente nomeados, se deixam notar pela conjugação dos verbos, assim como às suas temporalidades (se presente, passado, futuro: se aconteceram, acontecerão ou, no mais das vezes, acontecem, num presente absoluto). Assim, pronomes e advérbios, marcadores dêiticos - você, ele, aqui, lá, antes, agora -, 
que dependem de referências do presente da enunciação para ganharem sentido, quedam vazios, como setas apontando para onde não conseguimos ver.

Mas sobram também algumas falas que atravessam os versos, indicadas em itálico na página; e os cenários, na sua maioria urbanos - como o começo do poema "Liancourt 9", que diz: "como fazer para voltar se não traz / o bilhete lilás nem a carte / orange? conta duas portas / à direita e sobe a escada / -caracol" (GARCIA, 2007, p. 13). E por isso que eu dizia que os poemas são marcadamente visuais, como cenas que se desenrolam diante dos nossos olhos. Postos nas histórias, sem preparo ou maiores explicações, sentimos poder intuir os significados, tocá-los com as pontas dos dedos, sem poder agarrá-los.

A partir do seu próximo livro, porém, Engano geográfico, de 2012, a estrutura narrativa começa a mudar. Esse livro é composto por um único longo poema que narra uma viagem, tendo como interlocução e interferência direta o poema "dois andares com terraço e vista para o estreito", de Emmanuel Hocquard (1989), que, aliás, também é uma história de viagem (e, não por acaso, foi traduzido e estudado por Marília durante o seu doutorado na UFF).

É em Um teste de resistores (2014) que outro procedimento narrativo toma forma - a preocupação com uma poesia literal, movida pela busca de fatos concretos, datas cronológicas, espaços geográficos, pessoas biográficas. Aqui a sua escrita atinge um novo patamar. O primeiro poema, "Blind Light", começa assim:

\author{
poderia começar de muitas formas \\ e esse começo poderia ser um movimento ainda sem direção \\ que vai se definindo \\ durante o trajeto \\ poderia começar situando o tempo e o espaço \\ contexto hoje é quarta-feira dia 27 de novembro \\ e estamos no $3^{\circ}$ andar do centro universitário maria antonia \\ (GARCIA, 2014, p. 11)
}

A partir desse livro, o poema passa a se constituir como um espaço total de meditação sobre si, expondo, ensaiando, pensando tudo o que ocorre entre a história que narra, o procedimento que emprega e as considerações críticas e teóricas sobre essas duas dimensões do texto.

O que me parece ser um ponto de contato entre esses dois modos de narrar - entre as micronarrativas condensadas e o seu aparente oposto, o esforço pela narrativa fiel aos fatos - na verdade são dois: o primeiro é a contingência, a inevitabilidade dos acontecimentos que tomam forma de acaso (encontrado ou produzido) ou de desastre - desde a queima da resistência de um chuveiro ao acidente do voo da Malasya Airlines - que se tornam, porém, produtivos, porque forçam uma alteração - da rota, do planejamento, do estado de coisas - e 


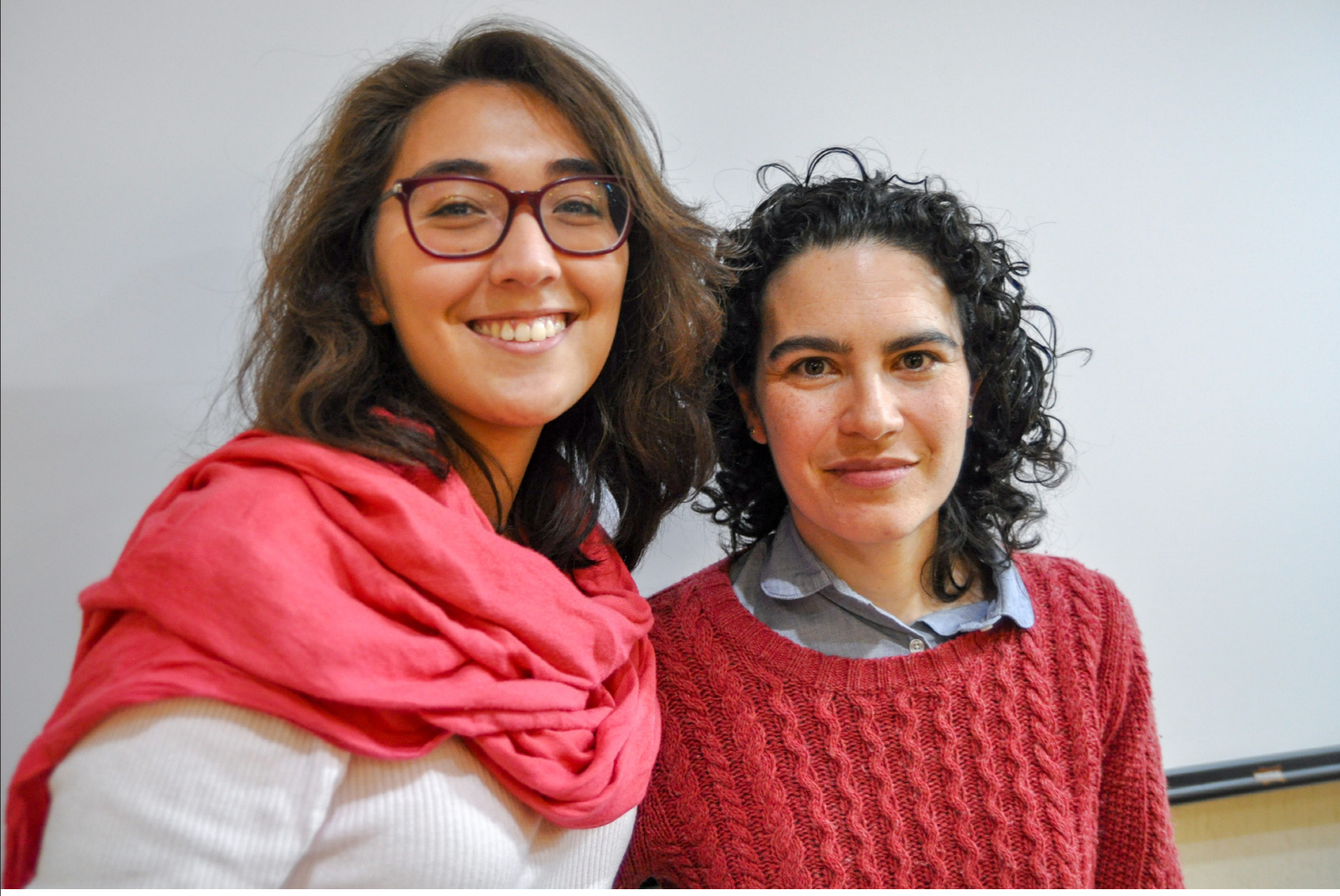

A escritora Marília Garcia e Julia Pasinato Izumino, mestranda do DTLLC.

provocam uma reflexão sobre a possibilidade de contar, sobre os modos de ver.

O segundo ponto de contato entre os modos de narrar é também, coincidentemente, o segundo ponto fundamental da poesia de Marília: o deslocamento. Viagens, idas, vindas estão presentes em todos os seus livros. Engano geográfico, já disse, é um poema meio diário de viagem; os poemas de Paris não tem centro (2016) nos levam a perambular por Paris a pé; Um teste de resistores conta várias viagens, travessias, caminhos.

Deslocamento entre as línguas também - dos países habitados e visitados, dos poemas traduzidos, vertidos, vergados -, como o próprio "Paris não tem centro", que foi escrito em francês e traduzido por outra pessoa para o português, e no livro é seguido por outro poema que pensa as dificuldades e tensões nascidas na língua a partir desse procedimento experimental.

Por isso que se diz que a poesia de Marília define uma cartografia própria, que é uma palavra muito precisa para se usar, já que o mapa, a imagem do mapa, as linhas sobre uma superfície - enfim, esse dispositivo visual para apreensão do território - surgem repetidamente nos seus textos. Mas a repetição da pergunta quanto à possibilidade de sobrepor mapas e então também as suas temporalidades - "porque se mapas podem se sobrepor/ sabe que o tempo não 
dobra/ apenas se vier o acaso fundamental" (GARCIA, 2012, p. 15) - nunca deixa de ressoar a lição do poema que se chama "le pays n'est pas la carte" (2007), que, se soa um pouco como o famoso "ceci n'est pas une pipe" do quadro Traição das imagens, de René Magritte (1928-1929), não é por acaso: ambas apontam para o mesmo fato, de que entre coisa e a representação da coisa há um intervalo que os torna irremediavelmente distintos.

Ainda pensando o deslocamento como tema, os meios de transporte - ou, melhor dizendo, os dispositivos de deslocamento - se tornam necessários. Carros, aviões (com e sem hélices), trens (que às vezes correm a direção contrária), helicópteros (e seus ruídos) atravessam a poesia, alimentam trânsitos e trocas, carregam o sujeito lírico de um ponto a outro - porque, como se percebe, aqui não falamos de um movimento errático, de um sujeito que vagueia pela urbe, mas estamos, sim, falando de percurso.

Nessa configuração, até o walkman e a câmera lenta - câmera-olho que provoca um movimento (lento) na percepção das cenas e dos acontecimentos - se tornam dispositivos de deslocamento, porque criam uma alteração nas formas de ver, ler, dispor, entender o mundo.

O que nos leva ao terceiro ponto fundamental, os procedimentos e a experimentação. A ligação vem do fato de que, aqui, todo procedimento parece

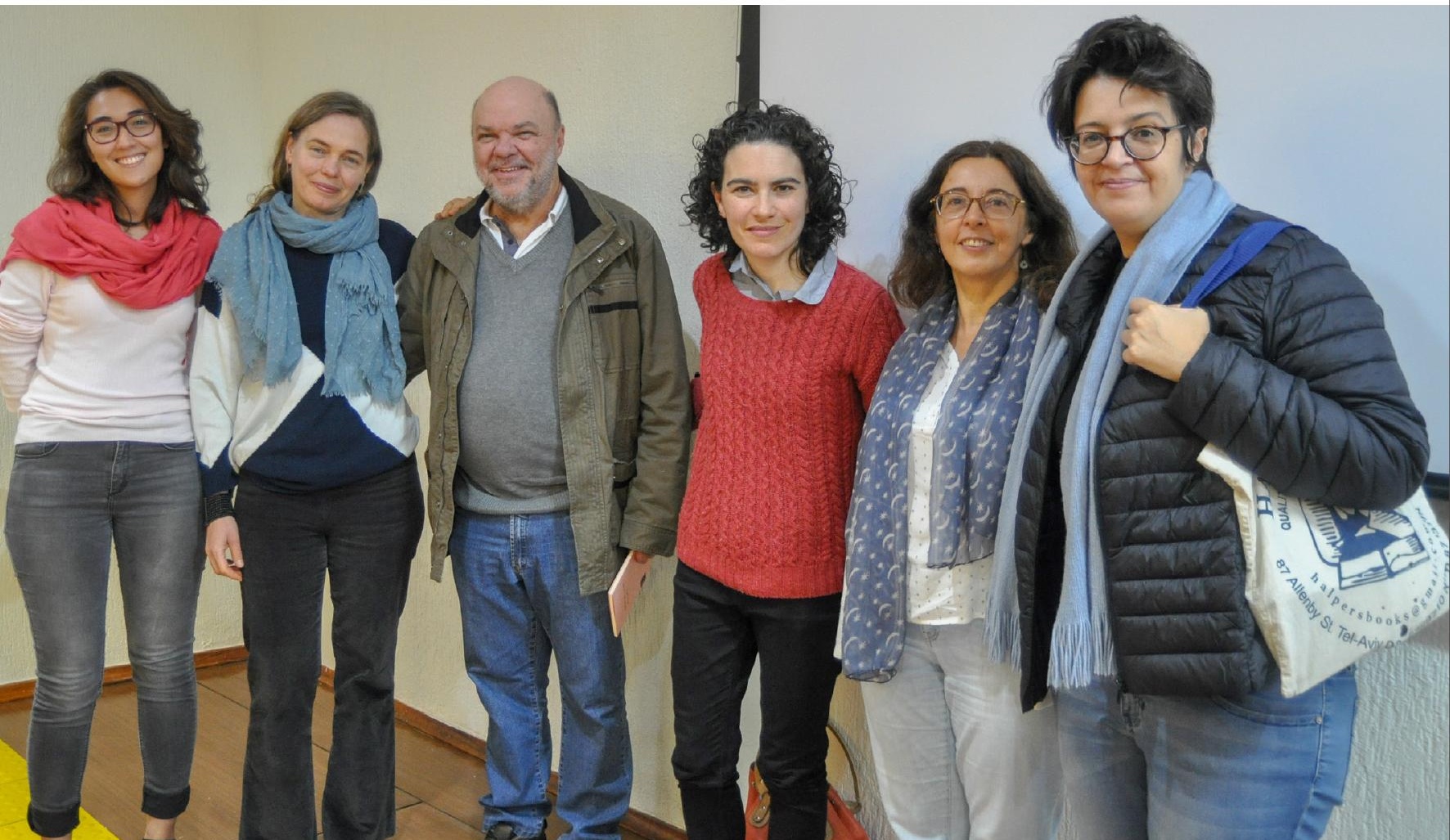


ser empregado para desafiar e estranhar o olhar, tentando descobrir novas possibilidades.

Assim, sobreposições, cortes, colagens, citações diretas e indiretas, repetições são operadas em variados graus de intensidade e transparência. Há toda uma constelação de referências - Ana Cristina Cesar, Leslie Kaplan, Haroldo de Campos, Jacques Roubaud, entre muitos outros - e cenas de filmes - de Jean-Luc Godard, David Perlov - que surgem incorporadas, roubadas, coladas, referidas.

Ainda se aproveita de trocas e diálogos, correspondências, perguntas da plateia. Aliás, a própria atividade de leitura em festivais e eventos é incorporada à poesia, tanto na forma, por exemplo ao elaborar repetições sintáticas, refrões e também espaços vazios e intervalos entre as palavras na mesma linha, criando pausas e momentos de respiro e silêncio, quanto no tema, como em "hola, spleen", um poema que se faz a partir da impossibilidade da sua própria leitura em público: "um dia quis ler em voz alta/ um poema chamado/“hola, spleen”,/ mas quando chegou a hora/ fiquei muito gripada/ e o que foi pior/ o que me impediu de ler/ foi que fiquei/ sem voz" (Garcia, 2017, p. 9).

Mais importante é que experimenta e, ao mesmo tempo, no mesmo texto, pensa sobre os procedimentos e experiências, talvez no melhor exemplo de uma poesia que "diz dizendo", como retoma de Roubaud. Por exemplo em "Blind Light", no qual reflete e discorre sobre o corte e a repetição enquanto opera o corte e a repetição, ou em "é uma love story e é sobre um acidente", de Câmera lenta (2017), em que escreve o poema e, imediatamente, reordena os versos em ordem alfabética (como fez também com a teus pés de Ana Cristina Cesar) - para "deslocar o contexto de onde tinham saído os versos/ para poder perceber outras relações a partir/ dos próprios versos" (GARCIA, 2014, p. 33).

O que se cria então é um equilíbrio muito delicado e muito raro de se encontrar: uma poesia que, ao mesmo tempo que nos provoca, porque nos obriga a encarar o estranhamento das coisas fora do lugar, dos sentidos reexplorados, do acaso que impera e de repente nos sacode, também se mostra muito generosa, ao nos pegar pela mão e nos levar para dentro da discussão, do cenário, da história, nos explicar o procedimento enquanto o faz operar à nossa frente, nos dando a chance de participar da conversa. I

JULIA PASINATO IZUMINO - Formada em Letras pela USP, atualmente desenvolve, no Programa de Teoria Literária e Literatura Comparada dessa instituição, trabalho de mestrado sobre a poesia de Ana Cristina Cesar e a fotografia de Vivian Maier. 


\section{REFERÊNCIAS BIBLIOGRÁFICAS}

Garcia, Marília. 20 poemas para o seu walkman. São Paulo: Cosac Naify; Rio de Janeiro: 7Letras, 2007.

GARCIA, Marília. Engano geográfico. Rio de Janeiro: 7Letras, 2012.

GARcia, Marília. Um teste de resistores. Rio de Janeiro: 7Letras, 2014.

Garcia, Marília. Paris não tem centro. Rio de Janeiro: 7Letras, 2016.

GARcIA, Marília. Câmera lenta. São Paulo: Companhia das Letras, 2017. 